Journal of Advanced Research in Fluid Mechanics and Thermal Sciences

\title{
Magnetic Polymer Based Micropumps for Microfluidic Sample Delivery System
}

\author{
Jumril Yunas ${ }^{1, *}$, Muzalifah Mohd Said ${ }^{2}$, Roer Eka Pawinanto ${ }^{3}$, Badariah Bais ${ }^{1}$, Budi Mulyanti ${ }^{3}$, Ida \\ Hamidah $^{3}$, Asep Bayu Dani Nandiyanto ${ }^{3}$, Burhanuddin Yeop Majlis ${ }^{1}$
}

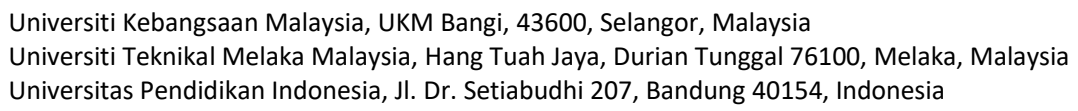

\section{ARTICLE INFO}

Article history:

Received 11 April 2021

Received in revised form 1 June 2021

Accepted 9 June 2021

Available online 26 July 2021

\section{Keywords:}

Electromagnetic micropump; polymer composites; microfluidic; MEMS; biomedical field

\section{ABSTRACT}

\section{Introduction}

The microfluidic platform has been playing important role in the sustainable development of MEMS device, especially for various biomedical applications. Several essential elements of biomedical instrumentations, such as HPLC (High Precision Liquid Chromatography), PCR (polymerized Chain Reaction), DNA Analysis, virus and bacterial detection system, drug delivery and lab on chip (LoC), have been built incorporating MEMS microfluidic devices that enable the devices to function with low sample volume, low power consumption, rapid and precise sample analysis as well [1-4].

A specific fluid handling in micro-scale channel is necessary, which is due to its specific characteristics of laminar flow property [5-9]. Therefore, the delivery of the microfluidic bio-sample requires the precision in sample injection which is mainly done through a controlled fluids pump from the reservoir into the microfluidic system.

\footnotetext{
* Corresponding author.

E-mail address: jumrilyunas@ukm.edu.my
}

https://doi.org/10.37934/arfmts.85.1.1221 
Various microfluidic pumping systems, such as piezoelectric pump [10], electrostatic pump [11] and thermal pneumatic pump system [12] have been reported previously. Meanwhile, some actuator membrane materials including metal, silicon, rubber etc., have been implemented to drive the fluid pumping which were unfortunately very robust and less flexible, hence reducing its pumping performance [13].

To overcome the problem, an electromagnetic (EM) micropump installed with more flexible actuator membrane would be the alternative choice to achieve an accurate and controlled dose of sample. Here, the polymer-based actuator has been found as the most suitable material due to its high flexibility and strong mechanical property [14].

The development history of the actuator for pumping purpose refers to the development of the actuator membrane material. Initially a thin silicon-based membrane with attached bulk permanent magnet was used as the actuating diaphragm [15]. Then, an electroplated magnetic material was deposited on a polymer membrane to replace the bulk magnet [16]. The disadvantage of the electroplated magnet is that the membrane system lost its flexible property. Therefore, an embedded magnetic particle had been found as the best alternative way to create a flexible membrane, which revealed good mechanical property and high magnetic property [17].

In this paper we discuss in detail the development of the microfluidic pump system incorporating of magnetic polymer composite-based actuator membrane. The magnetic membrane was synthesized by mixing the PDMS (Polydimethylsiloxane) with NdFeB magnetic particles which were then printed using soft lithography micro-molding process. The polymer composite membrane was combined with PDMS micro-channel and chamber to complete the microfluidic part of the pump system.

\section{Methodology}

\subsection{Design of the EM Micropump Structure}

The complete system of the EM micropump can be seen in Figure 1. It consists of PDMS based microfluidic parts (inlet/outlet tubing connection, micro channel with valve-less diffuser elements and pump chamber), the magneto-mechanical actuator system (including a thin film magnetic polymer membrane, magnetic chamber and NdFeB permanent magnet) and the electromagnetic field generator with a current carrying planar micro-coil on PCB lying perpendicular to the permanent magnet.

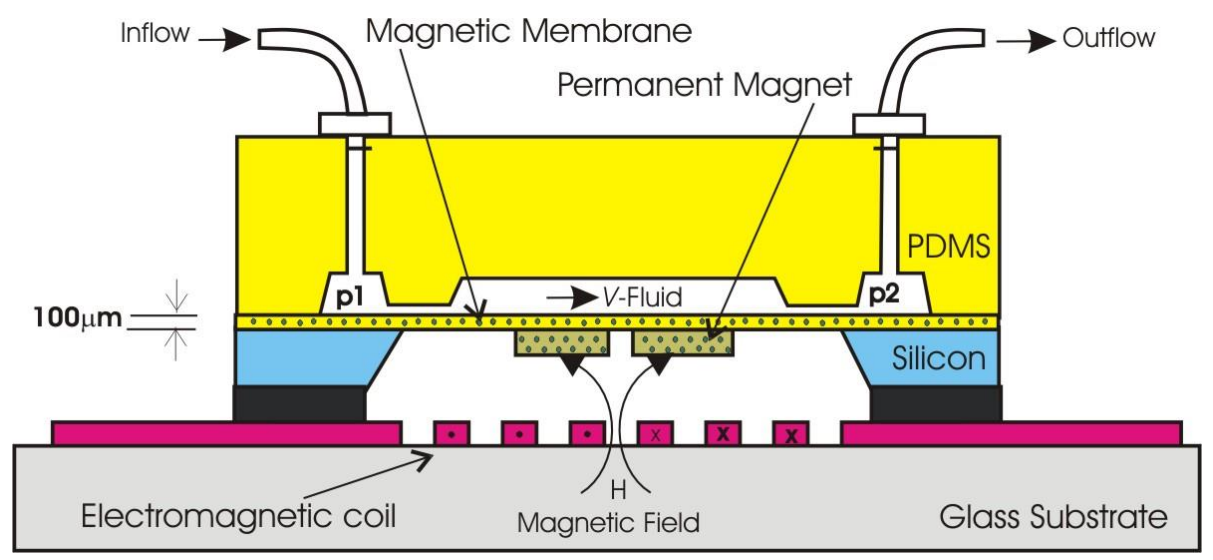

Fig. 1. The schematic of the polymer based electromagnetically driven microfluidic pump system 
The fluid pumping is happened due to the periodically membrane actuation in the pump chamber. For EM pump system, the theoretical actuation mechanism is referred to the Maxwell theory. When electrical alternating current flows through the micro-coils, magnetic field will be generated and interacts with the permanent magnet and produces magnetic force $\left(F_{z}\right)$ that finally causes the thin membrane to deform periodically.

$$
F_{z}=B_{r} A_{g} \int_{z}^{z+h_{g}} \frac{\partial H_{z}}{\partial_{z}} d z
$$

where, $B_{r}$ is the magnetic induction, $A_{g}$ is the surface area of the permanent magnet, $h_{g}$ is the height of the permanent magnet, while $H_{z}$ is the magnetic field in z-direction. The height of the center deflection $\left(d_{z}\right)$ of the membrane is given as follow,

$d_{z}=c \frac{F_{z} l_{m}^{2}}{h^{2}}\left(\frac{12\left(1-v^{2}\right)}{E h^{2}}\right)$

where, $F_{z}$ is the magnetic force, $I_{m}$ is the membrane size, $\mathrm{h}$ is the membrane thickness and $v$ is the Poisson's Ratio, while $E$ is the Young's Modulus

\subsection{Fabrication of the Micropump}

As shown in Figure 2, the microfluidic pump system is separately fabricated in 3 main steps, namely the fabrication of the electromagnetic coil part, the fabrication of the magneto-mechanical actuator parts and the fabrication of the microfluidic part. (see Figure 1).

The electromagnetic coil part is fabricated by electroplating the copper layer on PCB followed by the patterning the planar coil structure and etching the copper layer to form the spiral structure as shown in Figure 3(a).

The second step is the fabrication of the electromechanical actuator. The PDMS material is the basic material which is printed using molding process on an SU8 based mold master. The process is called as soft-lithography. The process is started with the synthesis of the magnetic membrane by mixing the PDMS with magnetic particles having the particle size of maximum $50 \mu \mathrm{m}$ with matrix pattern, followed by placing the thin magnetic PDMS membrane onto a silicon-based spacer (Figure $3(b))$. Finally, a permanent magnet is attached to the magnetic membrane

In the third step, the microfluidic part of the pump system is fabricated using micro-molding process. The molded PDMS structure is then transferred and bonded on to the pre-fabricated magneto-mechanical part. The tubing connections are also established at this step. To ensure the bonding quality, a corona discharge is applied. Figure $4(a)$ and (b) shows the results of the molding and bonding process. 


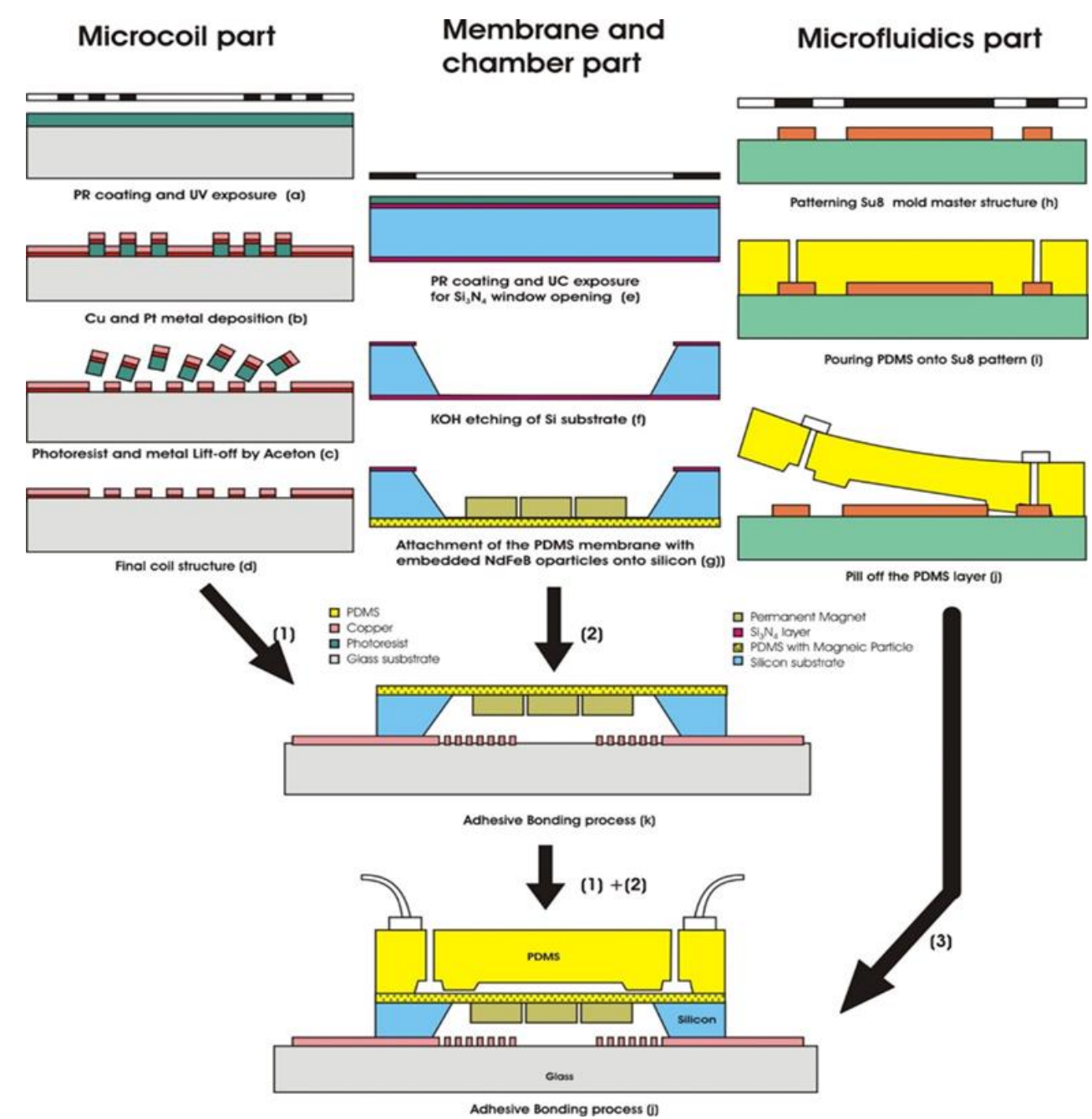

Fig. 2. Schematically process step for the fabrication of mechanical membrane and electromagnetic part

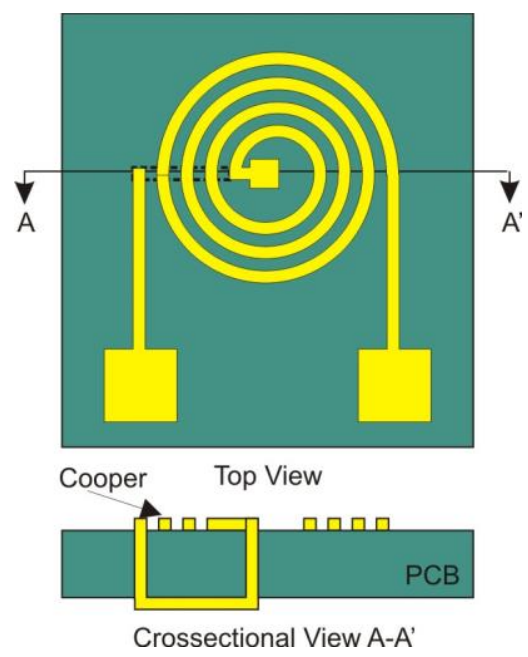

(a)

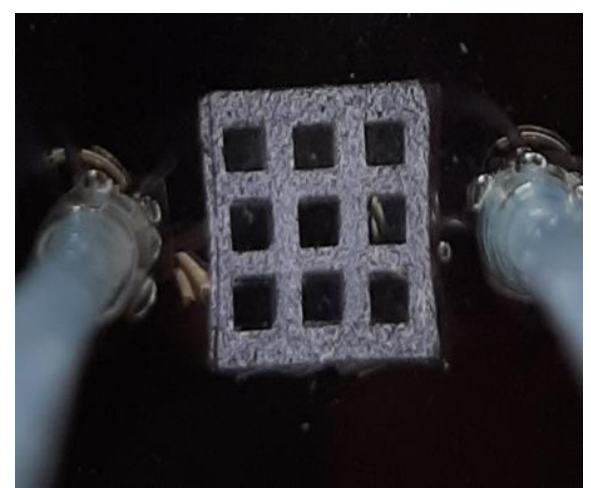

(b)

Fig. 3. (a) The schematic of the planar electromagnetic microcoil structure, and (b) the photograph of the fabricated matrix magnetic membrane 

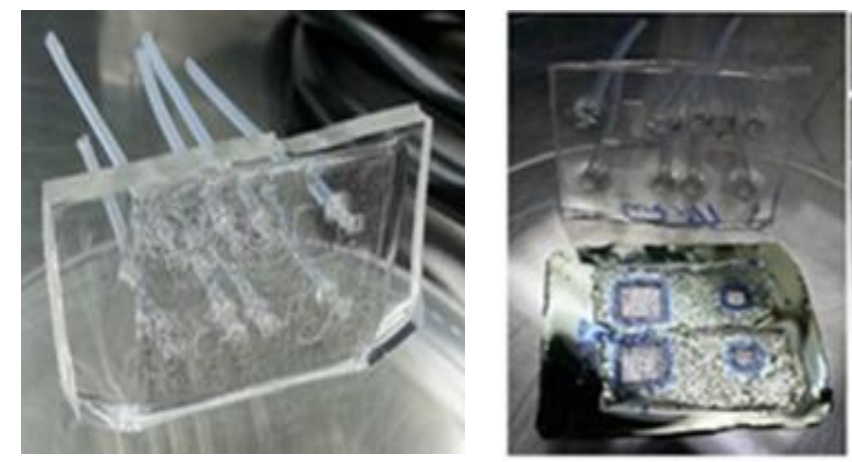

Fig. 4. (a) The molded PDMS ready for transfer, and

(b) the transfer of molded microfluidic layer onto the pre-fabricated actuator part (right)

The final step of the fabrication process is the integration of all parts. This step includes the bonding between the electromagnetic part and the pre-bonded magnetic actuator with microfluidic part. Figure 5 shows the final form of the micropump system.

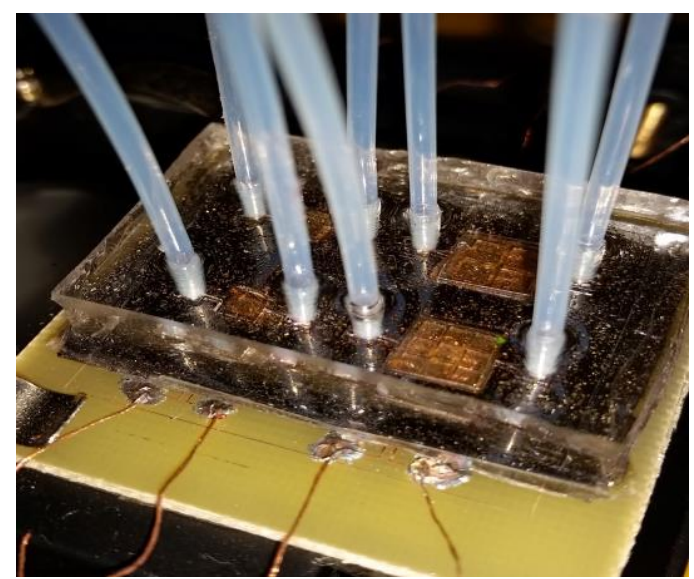

Fig. 5. The fabricated micropump system

\section{Results and Discussions}

\subsection{Actuator Test and Measurement Setup}

Our preliminary test was done on the actuator, as the functionality of the pump is strongly depending on the actuator performance. As shown in Figure 6, the measurement set up consists of a stabilized measurement stage, Gauss meter to see the intensity of magnetic field, Keyence LC2400 displacement meter with the laser probe, to see the height of membrane deformation, Ohm meter to measure the power consumption and power supply with function generator. 

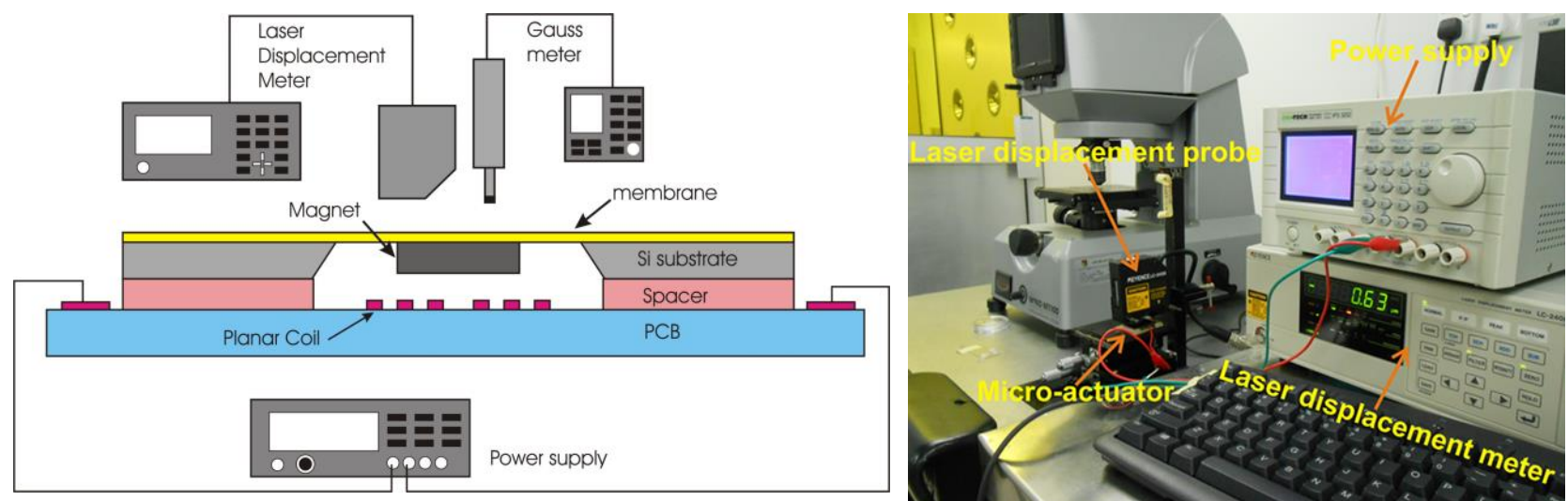

Fig. 6. (a) Schematic of the measurement setup for the actuator performance, and (b) the photograph of the setup

The planar coil parameters as the EM generator are based on the dimension of the electromagnetic coil and the type of the coil structure, such as planar spiral coil and planar parallel coil. As Shown in Table 1, the coil is made of electroplated spiral cooper having fix distance (space) between the winding and the varied coil width.

Table 1

The planar coil specification and its geometry

\begin{tabular}{lllll}
\hline Sample Number & \multicolumn{2}{l}{$\begin{array}{l}\text { Dimension } \\
\text { [um] }\end{array}$} & \multicolumn{2}{l}{ Micro-coils Type } \\
\cline { 2 - 5 } & width & space & R [ohm] & R[Ohm] \\
\hline Coil1 & 200 & 100 & 0.4 & 1 \\
Coil2 & 150 & 100 & 0.7 & 1.1 \\
Coil3 & 100 & 100 & 0.8 & 1 \\
\hline
\end{tabular}

Our preliminary measurement was done on silicon based magnetic membrane. The result showed that the electromagnetic coil was able to interact with the permanent magnet on silicon membrane and obtained a maximum membrane displacement of approximately $4.6 \mu \mathrm{m}$ for a power consumption of approximately 0.8 watt. This indicates that the coil is functioning properly and able to deform a flexible membrane with power as low as 1 watt. In Figure 7(a), it is shown that the deformation capability of EM membrane can be increased by increasing the electrical power.

After replacing the silicon membrane with polymer composite the membrane deflection obtained almost 20 times higher than that based of silicon for the same input power (Figure 7(b)). The functionality test of polymer membrane using pulsatile input current shows that the membrane actuator is able to deform periodically at low power consumption which is required for a compact peristaltic fluids pump application. 

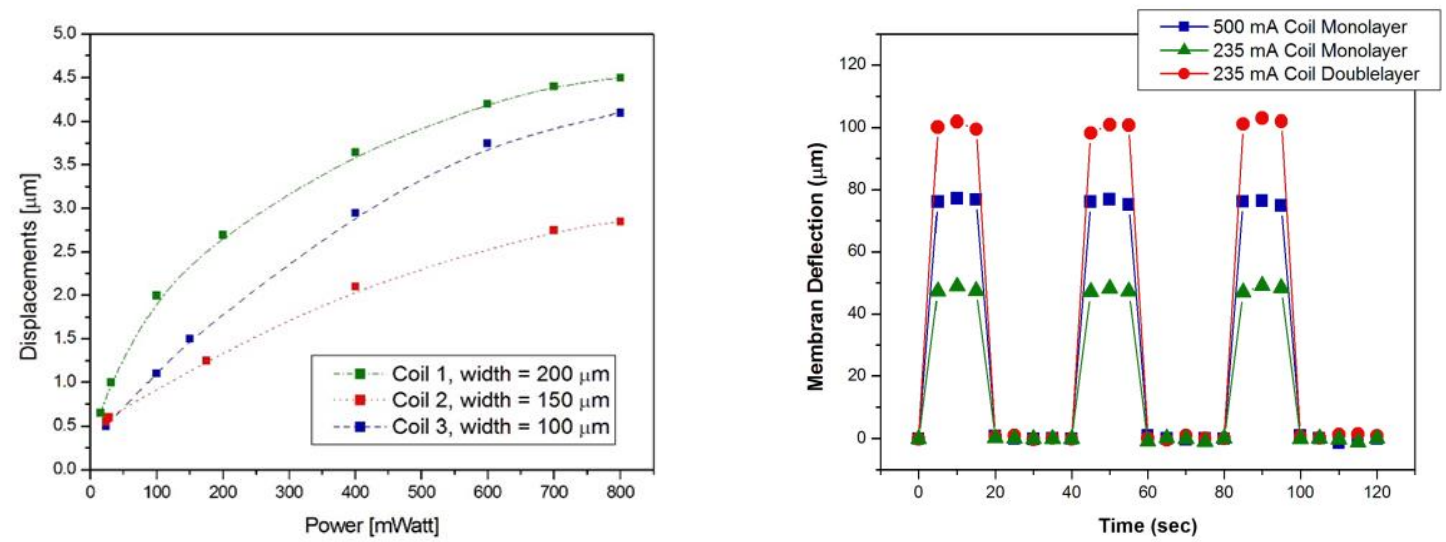

Fig. 7. Displacement characteristics of EM actuator having planar spiral type at various coil geometry and input power, (a) test on silicon membrane (b) test on polymer membrane with pulsatile input currents

\subsection{Pump Test and Measurement Set Up}

The functionality of the fabricated micro-pump was tested by observing the fluid flow from the reservoir to the observation tube channel in response to the membrane deformation, as shown in Figure 8. The fluid flow-rate is calculated as the length of fluid movements in the tube channel at certain observation time.

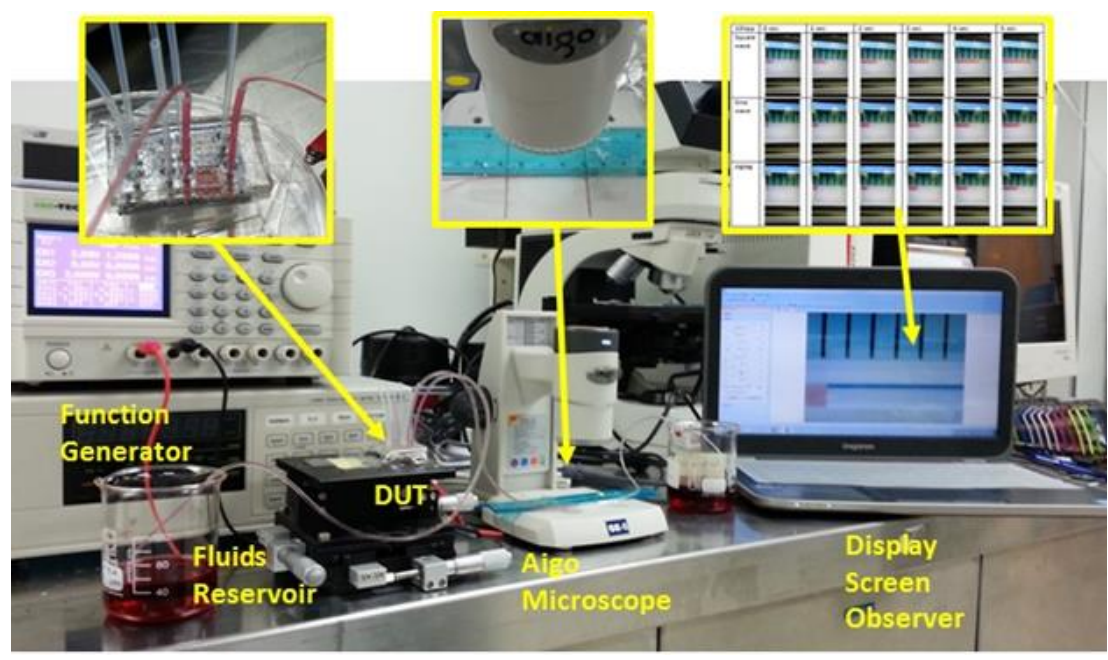

Fig. 8. The functionality test setup of the fabricated micro-actuator

The test parameter includes the input current amplitude of $500 \mathrm{~mA}$ with various current pulse, frequency and the polymer membrane types (matrix with and without attached permanent magnet). To improve the magnetic field generation, spiral coil with double layer was also experimented.

The fluid flow was initially tested on the pump with matrix patterned magnetic polymer composites membrane (Figure 9). The actuator functionality was tested for 120 seconds. The actuator square wave input current is able to drive the pump with maximum flow-rate of 6.5 $\mathrm{nL} / \mathrm{min}$. It can be seen that a slow pump rate was obtained at pump using a $2 \times 2$ matrix patterned magnetic polymer actuator membrane. A double electromagnetic coil can significantly increase flow-rate, as higher magnetic field intensity is generated. 


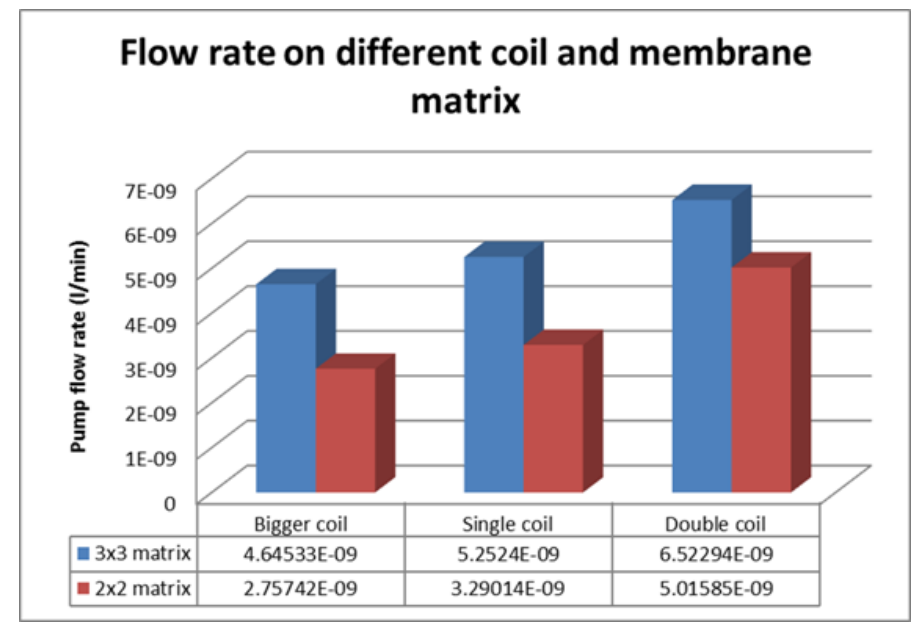

Fig. 9. The functionality test results of the fabricated micro-pump incorporating matrix magnetic polymer composite actuator membrane

The second attempts were done by implementing a bulk permanent magnet attached to the matrix magnetic polymer composite (hybrid type). As shown in Figure 10(a), a significant increase of the flowrate was achieved. It can be seen that the flow-rate of $48 \mathrm{~nL} / \mathrm{min}$ at the frequency of $1 \mathrm{kHz}$ was achieved. The flow-rate can be increased if higher pulse frequency of input current is used.

The next measurement was conducted by varying the signal type. It is shown that pulse type of the input current to drive the pump has significant influence to the pump performance. It is shown in Figure 10(b), a square pulse of current signal achieved the highest flow-rate compared to other pulse type. The microfluidic pump driven by electromagnetic coil with square wave input signal shows the highest flow-rate of approximately $6.6 \mu \mathrm{L} / \mathrm{min}$.

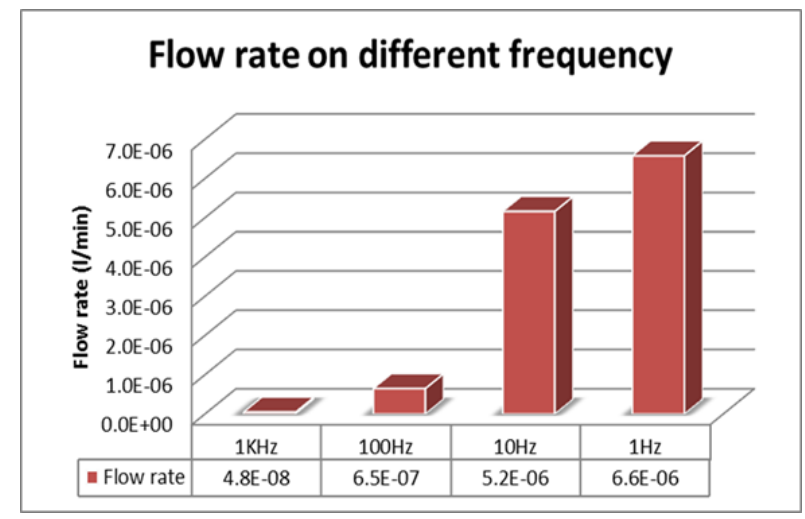

(a)

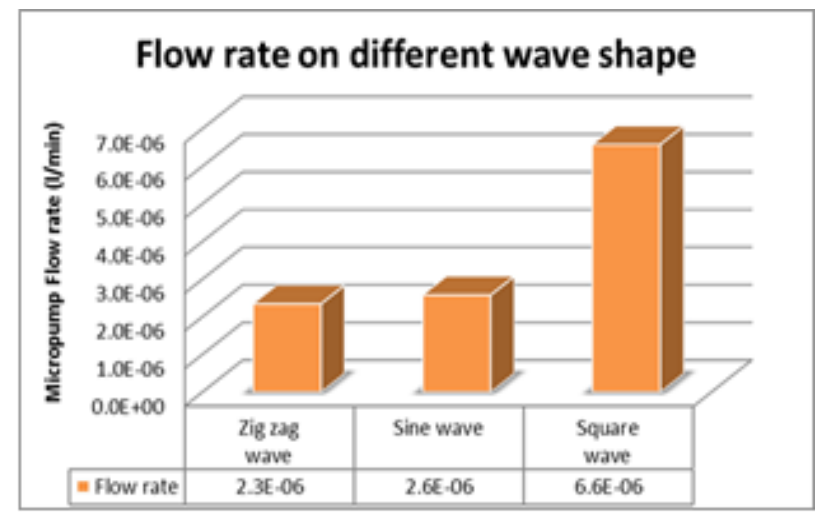

(b)

Fig. 10. The functionality test results of the fabricated micro-pump incorporating matrix magnetic polymer composite actuator membrane and attached permanent magnets. (a) the pump flow-rate at various frequency, (b) the pump flow-rate at various pulse type

\section{Conclusions}

A polymer based micropump for microfluidic delivery system was successfully fabricated using MEMS technique. The pump system includes the electromagnetic filed generator, mechanical flexible actuator membrane parts and the microfluidic part. The system can be fabricated separately with additional bonding. The initial measurement on the silicon based actuator membrane achieved a membrane deflection as high as only $4.6 \mu \mathrm{m}$ for only $1 \mathrm{~W}$ power 
consumption. The membrane deformation was improved by implementing a magnetic polymer composite membrane. The functionality test showed that the fabricated micropump with polymer magnetic composite membrane able to inject the fluid sample with the flow-rate within the range from $2.8 \mathrm{~nL} / \mathrm{min}$ to $6.6 \mu \mathrm{L} / \mathrm{min}$. The height of the flow-rate can be set by varying the input current amplitude, frequency and pulse type. The pump system will have its potential application to precisely deliver bio-sample in lab on chip, drugs delivery (such as for continuous insulin delivery), and injection of dialysate solution in Artificial kidney.

\section{Acknowledgement}

The authors would like to acknowledge the financial support from Universiti Kebangsaan Malaysia for supporting this project under HiCoE project: AKU254.

\section{References}

[1] Stipsitz, Martin, Georgios Kokkinis, Chinthaka Gooneratne, Jurgen Kosel, Susana Cardoso, Filipe Cardoso, and loanna Giouroudi. "Magnetic microfluidic platform for biomedical applications using magnetic nanoparticles." In Key Engineering Materials, vol. 644, pp. 207-210. Trans Tech Publications Ltd, 2015. https://doi.org/10.4028/www.scientific.net/KEM.644.207

[2] Wu, Jiandong, Meili Dong, Claudio Rigatto, Yong Liu, and Francis Lin. "Lab-on-chip technology for chronic disease diagnosis." NPJ digital medicine 1, no. 1 (2018): 1-11. https://doi.org/10.1038/s41746-017-0014-0

[3] Cui, Ping, and Sicen Wang. "Application of microfluidic chip technology in pharmaceutical analysis: A review." Journal of pharmaceutical analysis 9, no. 4 (2019): 238-247. https://doi.org/10.1016/i.jpha.2018.12.001

[4] Masrie, Marianah, Burhanuddin Yeop Majlis, and Jumril Yunas. "Fabrication of multilayer-PDMS based microfluidic device for bio-particles concentration detection." Bio-medical materials and engineering 24, no. 6 (2014): 1951-1958. https://doi.org/10.3233/BME-141004

[5] Muhammad, Nura Mu'az, and Nor Azwadi Che Sidik. "Utilisation of nanofluids in minichannel for heat transfer and fluid flow augmentation." Journal of Advanced Research Design 51, no. 1 (2018): 18-45.

[6] Amirouche, Farid, Yu Zhou, and Tom Johnson. "Current micropump technologies and their biomedical applications." Microsystem technologies 15, no. 5 (2009): 647-666. https://doi.org/10.1007/s00542-009-0804-7

[7] Shanko, Eriola-Sophia, Yoeri van de Burgt, Patrick D. Anderson, and Jaap MJ den Toonder. "Microfluidic magnetic mixing at low reynolds numbers and in stagnant fluids." Micromachines 10, no. 11 (2019): 731. https://doi.org/10.3390/mi10110731

[8] Paik, Phil, Vamsee K. Pamula, and Richard B. Fair. "Rapid droplet mixers for digital microfluidic systems." Lab on $a$ Chip 3, no. 4 (2003): 253-259. https://doi.org/10.1039/B307628H

[9] Ferdows, Mohammad, Mohammed Shamshuddin, and Khairy Zaimi. "Computation of Steady Free Convective Boundary Layer Viscous Fluid Flow and Heat Transfer towards the Moving Flat subjected to Suction/Injection Effects." CFD Letters 13, no. 3 (2021): 16-24. https://doi.org/10.37934/cfdl.13.3.1624

[10] Johari, Juliana, Jumril Yunas, Azrul Azlan Hamzah, and Burhanuddin Yeop Majlis. "Piezoelectric micropump with nanoliter per minute flow for drug delivery systems." Sains Malaysiana 40, no. 3 (2011): 275-281.

[11] Français, Olivier, and Isabelle Dufour. "Enhancement of elementary displaced volume with electrostatically actuated diaphragms: application to electrostatic micropumps." Journal of Micromechanics and Microengineering 10, no. 2 (2000): 282. https://doi.org/10.1088/0960-1317/10/2/330

[12] Cooney, Christopher G., and Bruce C. Towe. "A thermopneumatic dispensing micropump." Sensors and Actuators A: Physical 116, no. 3 (2004): 519-524. https://doi.org/10.1016/j.sna.2004.05.015

[13] Yunas, Jumril, Budi Mulyanti, Ida Hamidah, Muzalifah Mohd Said, Roer Eka Pawinanto, Wan Amar Fikri Wan Ali, Ayub Subandi, Azrul Azlan Hamzah, Rhonira Latif, and Burhanuddin Yeop Majlis. "Polymer-based MEMS electromagnetic actuator for biomedical application: a review." Polymers 12, no. 5 (2020): 1184. https://doi.org/10.3390/polym12051184

[14] Grujić, Aleksandar, Nadežda M. Talijan, D. Stojanović, Jasna Stajić-Trošić, Z. Burzić, Ljubiša Balanović, and Radoslav Aleksić. "Mechanical and magnetic properties of composite materials with polymer matrix." Journal of Mining and Metallurgy B: Metallurgy 46, no. 1 (2010): 25-32. https://doi.org/10.2298/JMMB1001025G

[15] Pawinanto, Roer Eka, Jumril Yunas, Muzalifah Mohd Said, Burhanudin Yeop Majlis, and Azrul Azlan Hamzah. "Design consideration of planar embedded micro-coils for electromagnetic actuator of fluids injection system." Middle-East J. Sci. Res 19, no. 4 (2014): 538-543. 
[16] Su, Yufeng, and Wenyuan Chen. "Investigation on electromagnetic microactuator and its application in microelectro-mechanical system (MEMS)." In 2007 International Conference on Mechatronics and Automation, pp. 3250-3254. IEEE, 2007. https://doi.org/10.1109/ICMA.2007.4304082

[17] Said, Muzalifah Mohd, Jumril Yunas, Roer Eka Pawinanto, Burhanuddin Yeop Majlis, and Badariah Bais. "PDMS based electromagnetic actuator membrane with embedded magnetic particles in polymer composite." Sensors and Actuators A: Physical 245 (2016): 85-96. https://doi.org/10.1016/i.sna.2016.05.007 